\title{
Role of Ultrasonography and MRI in Diagnosing Different Types of Adnexal Masses
}

\author{
Dr. Atishi Gupta Aggarwal ${ }^{1 *}$, Dr. Rohit Aggarwal ${ }^{2}$, Dr. BP Baruah ${ }^{3}$
}

${ }^{1}$ Junior Resident, School of Medical Sciences \& Research, Sharda University, Greater Noida, Uttar Pradesh, India

${ }^{2}$ Senior Resident, Noida International Institute of Medical Sciences, Noida International University, Greater Noida, Uttar Pradesh, India

${ }^{3}$ Professor, Department of Radiodiagnosis, School of Medical Sciences \& Research, Sharda University, Greater Noida, Uttar Pradesh, India

DOI: $10.36347 /$ sjams.2021.v09i01.031

| Received: 26.12.2020| Accepted: 11.01.2021| Published: 30.01.2021

*Corresponding author: Atishi Gupta Aggarwal

\section{Abstract}

\section{Original Research Article}

Adnexal mass lesions are common among women of all age groups and very common among the reproductive age group. Adnexal masses are usually identified either through clinical examination or through USG examination of the pelvis for symptoms caused by the mass or incidentally. USG is typically the first study to be requested in patients with clinical findings that may suggest pelvic disease. Adnexal masses pose a special dilemma to the attending gynaecologist because the differential diagnosis is often difficult and complex. With recent advances in the field of magnetic resonance imaging, MRI has become an important modality on the evaluation of a female pelvis. This study included 40 patients who were diagnosed with adnexal mass on USG and later underwent MRI which helps in providing definitive diagnosis with its superior soft tissue characterization, larger field of view and direct multiplanar capabilities.

Keywords: USG- Ultrasonography, CT - Computed Tomography, MRI - Magnetic Resonance imaging, STIR - Short Tau Inversion Recovery.

Copyright $\odot 2021$ The Author(s): This is an open-access article distributed under the terms of the Creative Commons Attribution 4.0 International License (CC BY-NC 4.0) which permits unrestricted use, distribution, and reproduction in any medium for non-commercial use provided the original author and source are credited.

\section{INTRODUCTION}

Adnexal mass lesions are common among women of all age groups and very common among the reproductive agegroup. Adnexal masses are quite common presentation of a gynaecological pathology. These adnexal masses can vary from benign masses like functional cysts to malignant masses like ovarian cancer. Fortunately, the benign lesions far outnumber the malignant ones. When the benign lesions are clinically insignificant or asymptomatic they can be followed up with USG or even ignored. Symptomatic benign lesions may require simple procedures whereas malignant lesions will require radical surgery.

Adnexal masses pose a special dilemma to the attending gynaecologist because the differential diagnosis is often difficult and complex. Also, the nature of the adnexal mass needs to be ascertained, whether benign or malignant, so that the patient gets the appropriate treatment for the condition.

Determining the benign nature of the mass and in some cases where MRI provides definitive diagnosis with its superior soft tissue characterization will not only save the patient from unnecessary surgery but also alleviate patients worry. On the other hand, malignant masses need to be identified as early as possible so that the patient gets the appropriate treatment.

Adnexal masses are usually identified either through clinical examination or through USG examination of the pelvis for symptoms caused by the mass or incidentally.

USG is typically the first study to be requested in patients with clinical findings that may suggest pelvic disease. Evaluation of adnexal masses is a common component of a sonologist's workload. The advantages of USG being its wide availability, decreased costs, safety and simplicity of the examination. USG has been shown to be accurate for both detecting and characterizing adnexal mass. Given the above mentioned advantages USG is the modality of choice for imaging suspected adnexal masses. However, the shortcomings with this modality includes limited field of view, obscuration of pelvic organs by the presence of bowel gas, inherent limitation dependent on patient size 
and its dependence on the skill and experience of the operator.

With recent advances in the field of magnetic resonance imaging, MRI has become an important modality on the evaluation of a female pelvis. MRI because of its excellent soft tissue contrast, larger field of view and direct multiplanar capabilities, can better delineate and characterize normal pelvic anatomy and adnexal pathology. MRI has been found to be highly accurate in the characterization of adnexal masses. MRI is non-invasive, has no risk of radiation, requires no anesthesia and is less operator dependent. MRI is considered as the next step in assessment of sonologically indeterminate masses and as the primary modality for evaluating gynecological malignancies. However, MRI is more expensive and potentially less readily available than USG.

\section{Aim and ObJectives}

- To note the advantages and limitations of one modality over the other vis- a- vis the evaluation of adnexal mass lesions.

- To suggest a guideline for imaging based on above results.

- To study the spectrum of diverse nature of adnexal mass lesions.

- To assess the role of MRI in evaluating sonologically indeterminate masses.

\section{Inclusion Criteria}

- Clinically suspected cases of adnexal mass lesions.

- Adnexal mass lesions found incidentally on USG.

\section{Exclusion Criteria}

- All midline uterine mass lesions.

- Clinically and sonologically proved cases of ectopic pregnancy.

- All Patients having cardiac pacemakers, prosthetic heart valves, cochlear implants or any metallic implants.

- Patients having history of claustrophobia.

\section{REVIEW OF LITERATURE IMAGING IN ADNEXAL LESIONS Ultrasonogram}

Till date Ultrasonography is the primary imaging modality of choice for pelvic mass evaluation because of its easy availability, cost effectiveness, high sensitivity and absence of ionizing radiation [4].

\section{Color Doppler}

Resistive index identified using color Doppler can be used to differentiate benign and malignant neoplasms. Resistive index less than 0.4 is considered suspicious of malignancy [4].
Lack of uniqueness and overlap of findings limits the utility of Color Doppler as a primary modality of investigations for neoplasms [4].

\section{Computed Tomography [5]}

Computed tomography has advantages of obtaining thinner sections and better spatial resolution. Because of faster imaging, CT is used for characterization of adnexal mass and staging work-up of ovarian malignancy. Computed Tomography has $79 \%$ sensitivity and $75 \%$ specificity indicating suboptimal prediction of cytoreduction.

\section{Magnetic Resonance Imaging}

In most cases Contrast Enhanced Magnetic Resonance Imaging is of great help in differentiating benign and malignant ovarian mass due to better characterization of tissues and excellent delineation of anatomical structures [6].

Study by Reles et al., showed that the sensitivity of colourdoppler US in premenopausal patients was $80 \%$ and specificity only $67 \%$, whereas the sensitivity and specificity were $93 \%$ and $83 \%$, in postmenopausal patients respectively [7].

MR imaging is superior to Doppler US in characterization of malignant ovarian disease [8].

Guerra et al., showed that MRI has a higher accuracy of $95 \%$ in differentiating between malignant and non-malignant adnexal lesions [9].

Valentini et al., substantiated the findings of Saini et al., about MRI imaging features of malignant adnexal neoplasm. He added that "heterogeneous and early enhancement pattern of lesion" is also suggestive of malignancy [10].

MRI serves as a sensitive and specific investigation compared to Doppler ultrasound and contrast enhanced CT in characterization of masses [8].

Sonographically indeterminate ovarian mass lesions evaluated with MRI had a sensitivity and specificity of $100 \%$ and $94 \%$, respectively [11].

Borderline ovarian tumors showing early enhancement is a better predictor of malignancy than CA-125 levels and sonographic findings [12].

The following criteria is used for diagnosis of malignant adnexal lesions with MR imaging [13].

- Mass size larger than $4 \mathrm{~cm}$.

- Predominantly solid lesions.

- Presence of necrosis on contrast-enhanced solid lesions.

- Contrast-enhanced papillary projections.

- Septal thickness $3 \mathrm{~mm}$ in cystic lesions.

- Bilaterality. 
Younger age groups are more prone to develop benign epithelial tumors and these lesions are predominantly cystic in appearance [14].

Malignant epithelial tumors have major solid components and few cystic structures. The two most common subtypes of epithelial neoplasms are serous and mucinous tumors [14].

The striking characteristic feature of surface epithelial neoplastic tumor of the ovary is papillary projections [15].

Hypointense fibrous core with a hyperintensestroma that is edematous demonstrated on T2 weighted MR image is a single best predictor of epithelial ovarian tumor. This feature correlates with the aggressive nature of the tumor [15].

\section{Benign epithelial tumors [16]}

- Diameter less than $4 \mathrm{~cm}$.

- Entirely cystic component.

- Wall thickness less than $3 \mathrm{~mm}$.

- Lack of internal structure.

- Absence of both ascites.

\section{STAGING OF OVARIAN CARCINOMA [18] \\ FIGO Staging of ovarian carcinoma Stage \\ Stage I: Tumour limited to ovaries.}

Ia - Tumor limited to one ovary, capsule intact, no tumor on ovarian surface, no malignant cells in ascites or peritoneal washings.

Ib - tumor limited to both ovaries, capsule intact, no tumor on ovarian surface, no malignant cells in ascites or peritoneal washings.

Ic - Tumor limited to one or both ovaries with any of the following: capsule rupture, tumor on ovarian surface, malignant cells in ascites or peritoneal washings.

Stage II: Tumor involves one or both ovaries with pelvic extensions or implants.

IIa- Tumor involves uterus or fallopian tubes, no malignant cells in ascites or peritoneal washings.

IIb- Tumor involves other pelvic tissues, no malignant cells in ascites or peritoneal washings.

Stage III: Tumor involves one or both ovaries with microscopically confirmed peritoneal metastasis outside the pelvis

IIIa - Microscopicaly confirmed peritoneal metastasis outside the pelvis.

IIIb - Macroscopicaly peritoneal metastasis outside the pelvis $<2 \mathrm{~cm}$.

IIIc - Macroscopicaly peritoneal metastasis outside the pelvis $>2 \mathrm{~cm}$.

Stage IV: Distant metastasis beyond the peritoneal cavity.

Enlarged lymph nodes above renal hilum.

TREATMENT
\begin{tabular}{|l|l|}
\hline STAGE & TREATMENT \\
\hline I & Primary cytoreduction \\
\hline II & Primary cytoreduction \\
\hline III & $\begin{array}{l}\text { Neoadjuvant chemotherapy and interval } \\
\text { cytoreduction }\end{array}$ \\
\hline IV & Neoadjuvant chemotherapy \\
\hline
\end{tabular}

\section{CLASSIFICATION OF OVARIAN TUMORS [17]}

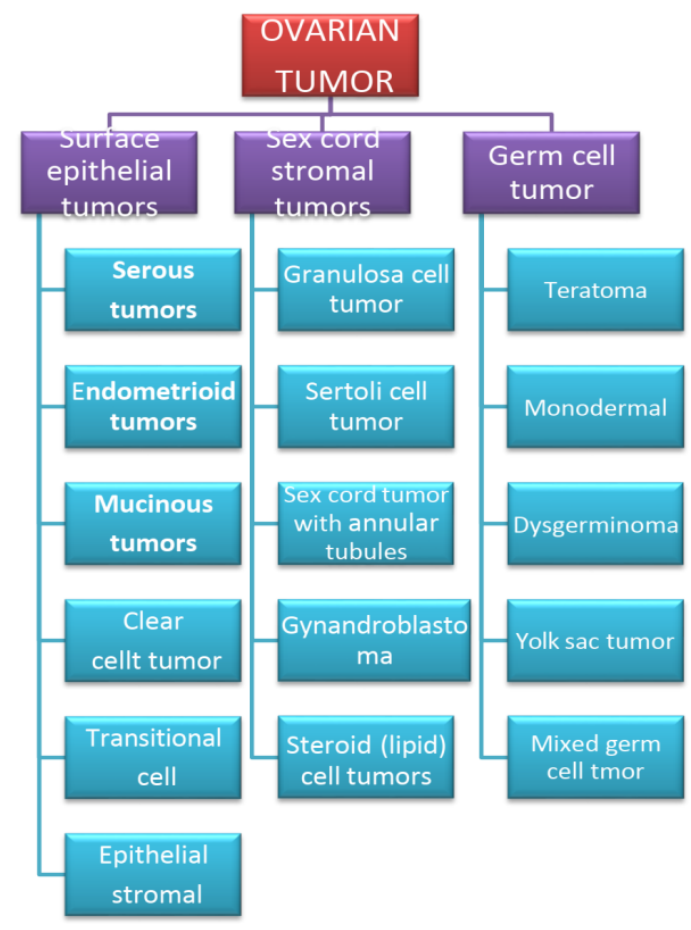

\section{Materials And Methods}

At our institution female patients presenting with lower abdominal pain and menstrual irregularities are evaluated in Department of Obstetrics and Gynecology and then referred to Department of Radio diagnosis for radiological evaluation.

Forty patients were referred for evaluation of Ultrasonography and contrast MRI. The patients were first subjected to ultrasound then dynamic MR imaging was done. The study was conducted after obtaining proper informed consent from the patient. As this was a prospective controlled study, ethical committee approval from Institutional Ethics Committee was obtained.

All patients are subjected to transabdominal sonography using curvilinear probe.

In Ultrasonogram adnexal lesions were evaluated for several features including content, nodularity, wall thickness, septal thickness, ascites and vascularity of the lesion. 
Then these patients are subjected to MRI and the following imaging features are evaluated.

The Dynamic MR imaging features documented for evaluation include the lesion size, content of lesion (solid only, mainly solid, solid- cystic, mainly cystic, and cystic only), wall thickness, nodularity, septal thickness, early arterial phase enhancement, ascites, omental deposits and lymphadenopathy.

\section{STUDY DESIGN}

All patients are subjected to Transabdominal sonography using curvilinear probe in PHILIPS EPIQ $7 \mathrm{G}$ and SAMSUNG SONOACE R7.

Axial and sagittal images of adnexal mass lesions are taken and then colourdoppler images also taken. The patients were subjected to magnetic resonance imaging using

Tesla PHILIPS ACHEIVA. The patients were examined in supine position and following sequences were taken: T1 axial, T2 sagittal / coronal, STIR coronal, T1 contrast axial and coronal Protocol used was: T2 W Axial: TR: $3776 \mathrm{~ms}$, TE: $90 \mathrm{~ms}$, Flip angle 90* Slice thickness 5mm, Matrix 400 x 305

T1 W Axial: TR: $503 \mathrm{~ms}$, TE: $10 \mathrm{~ms}$, Flip angle 90* Slice thickness 5mm, Matrix 344 x 289

STIR: TR: $4662 \mathrm{~ms}$, TE: $85 \mathrm{~ms}$, Slice thickness $5 \mathrm{~mm}$, Matrix 276 x 219

Contrast enhanced T1 images: Contrast-enhanced images were obtained after IV injection of $10 \mathrm{ml}$ gadolinium. The dynamic contrast-enhanced fatsuppressed T1-weighted MR imaging was performed through the lesion in the optimal plane.

This sequence was performed before and immediately after a rapid.

Hand IV injection of $10 \mathrm{ml}$ of gadolinium and then repeated at 30,60, 90 and $120 \mathrm{sec}$.

TR: 528 TE:10 Flip angle: 90-degree Slice thickness: 5mm Matrix: 344 x 289

\section{CASES}

Case-1: 38 years female patient presented with lower abdominal pain.

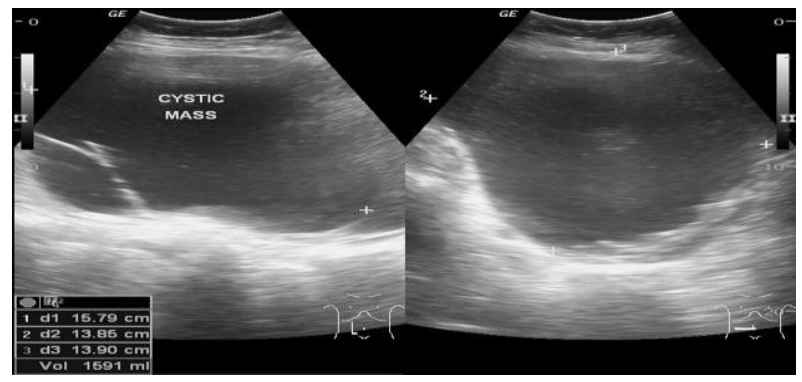

USG shows well defined cystic lesion with multiple septations and nodularity

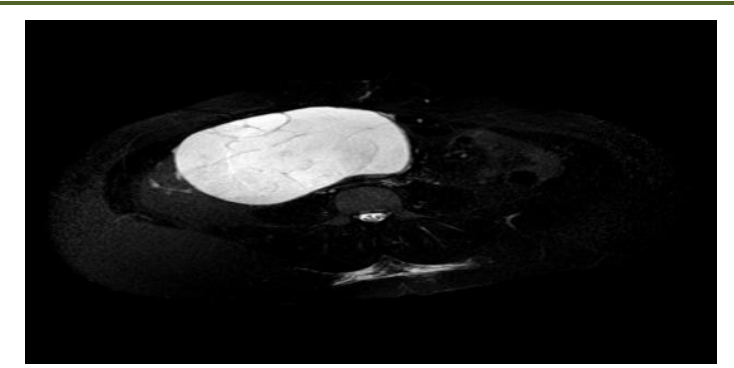

STIR images shows cystic lesion with septation and nodularity

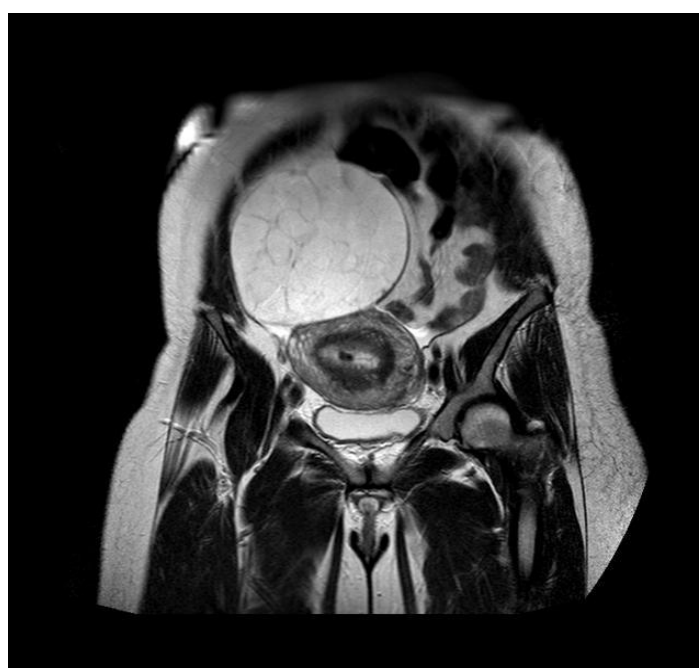

T2W images showing hyperintense lesion with septation and nodularity

Case-2: 32 years female patient presented with lower abdominal pain

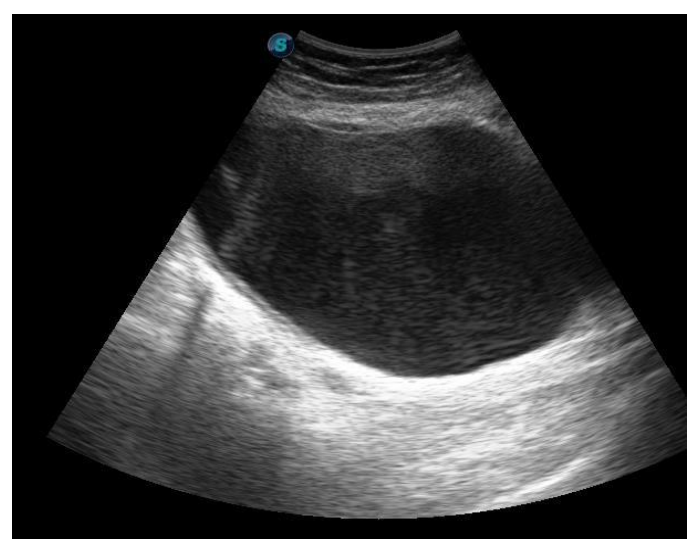

USG shows well defined cystic lesion in adnexa - Benign

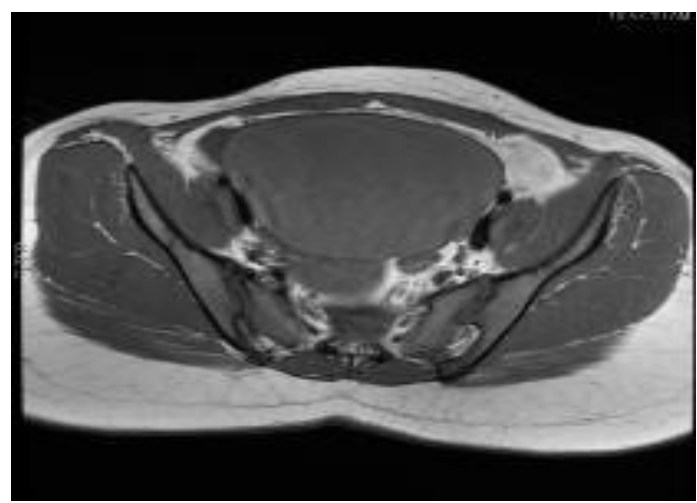

Well-defined T1- Hypointense cystic lesion in adnexa 
Atishi Gupta Aggarwal et al; Sch J App Med Sci, Jan, 2021; 9(1): 160-171

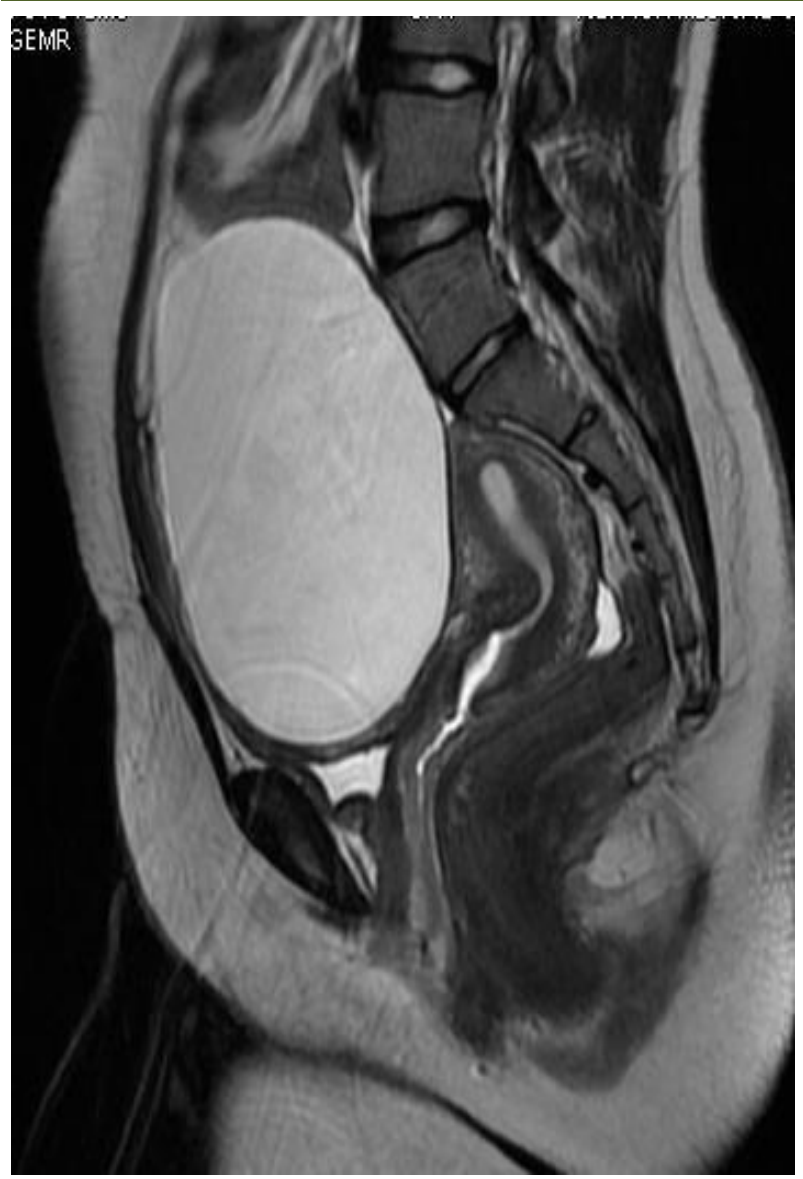

Well-defined T2- Hyperintense cystic lesion in adnexa - Benign
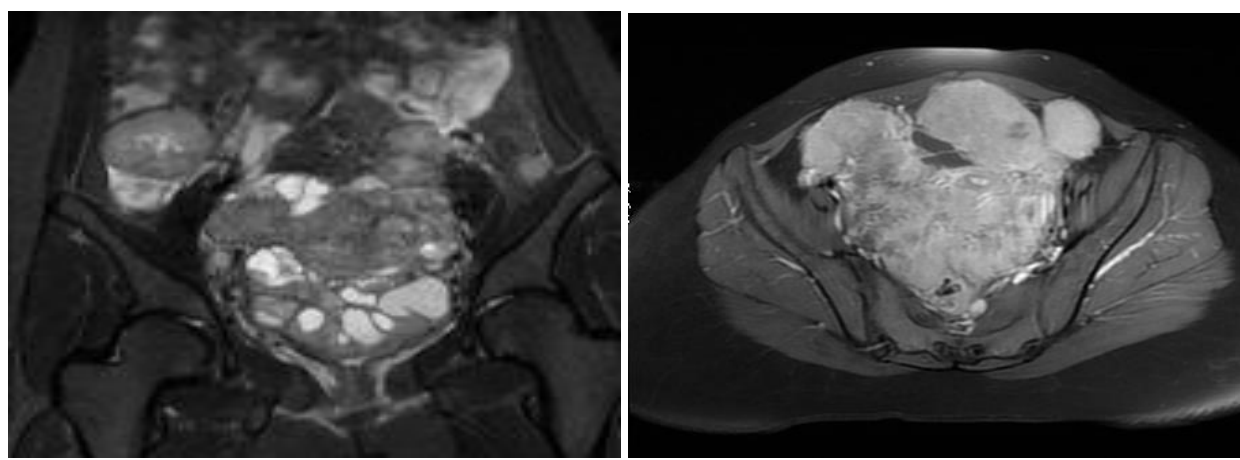

T2 \& STIR: Heterointense lesion with cystic and solid component noted in bilateral adnexa with omental deposits.

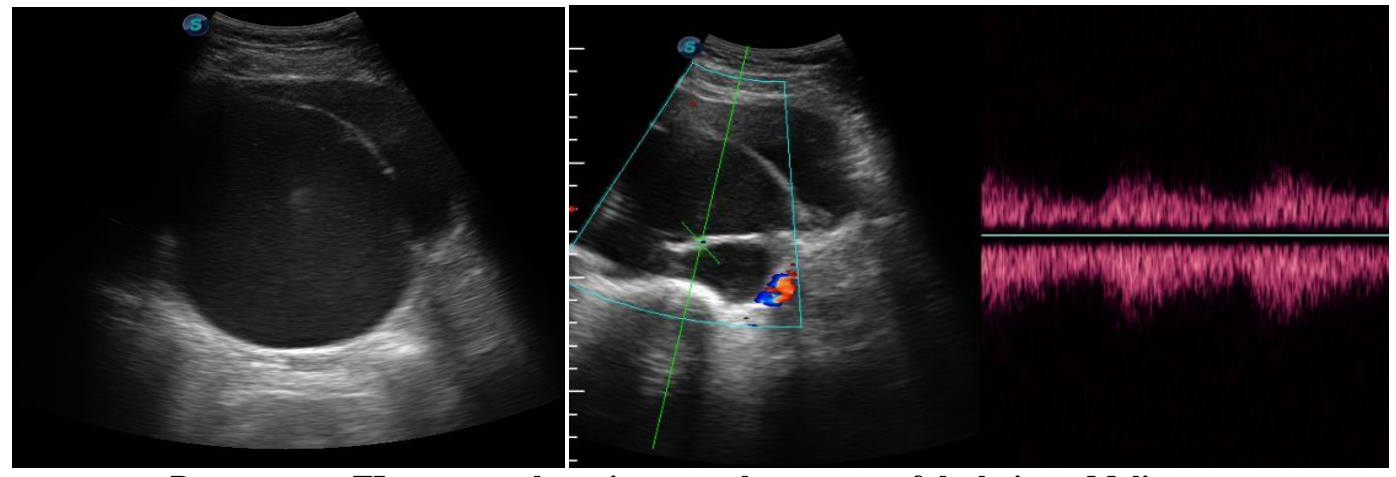

Post contrast TI sequence shows intense enhancement of the lesion - Malignant HPE shows: Surface epithelial malignant tumour

Case-3: 21 years female patient presented with abdominal pain and menstrual irregularities.

\section{USG shows heteroechoic lesion in bilateral adnexa}

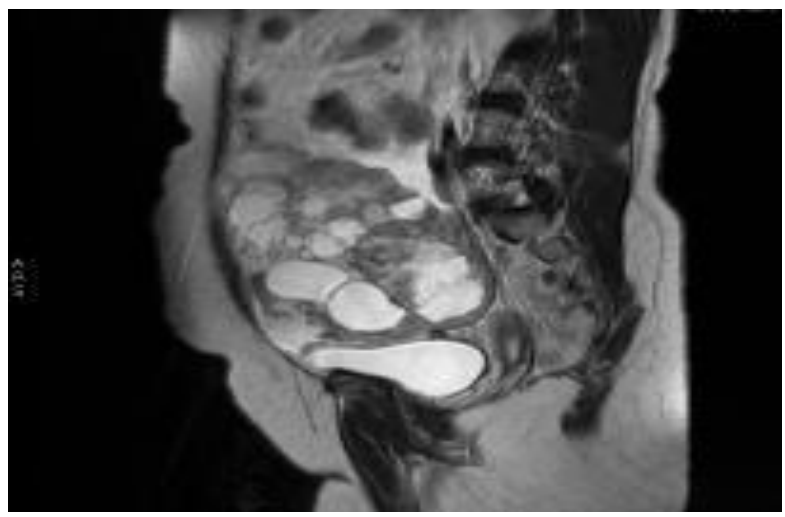

USG Doppler shows central vascularity - Malignant 
Case-4: 45 years female patient presented with abdominal pain and menstrual irregularities.

Well defined cystic lesion with septation in adnexa with peripheral vascularity - Benign

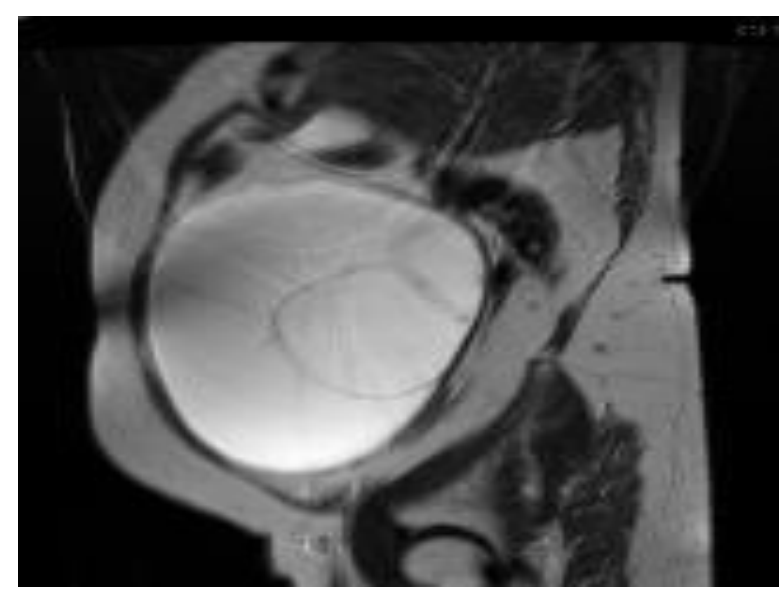

Well-defined T2 hyperintense lesion with septation in adnexa - Benign

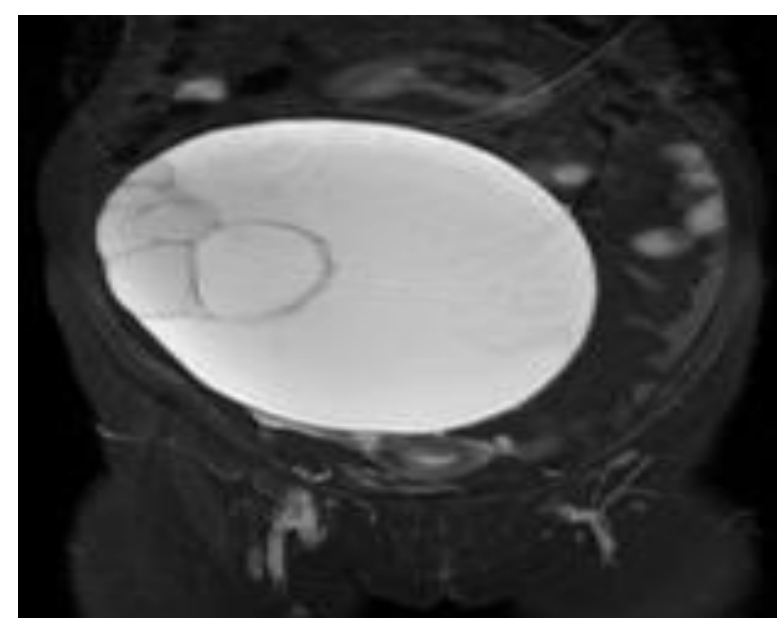

Well defined STIR Hyperintense cystic lesion with septation in adnexa

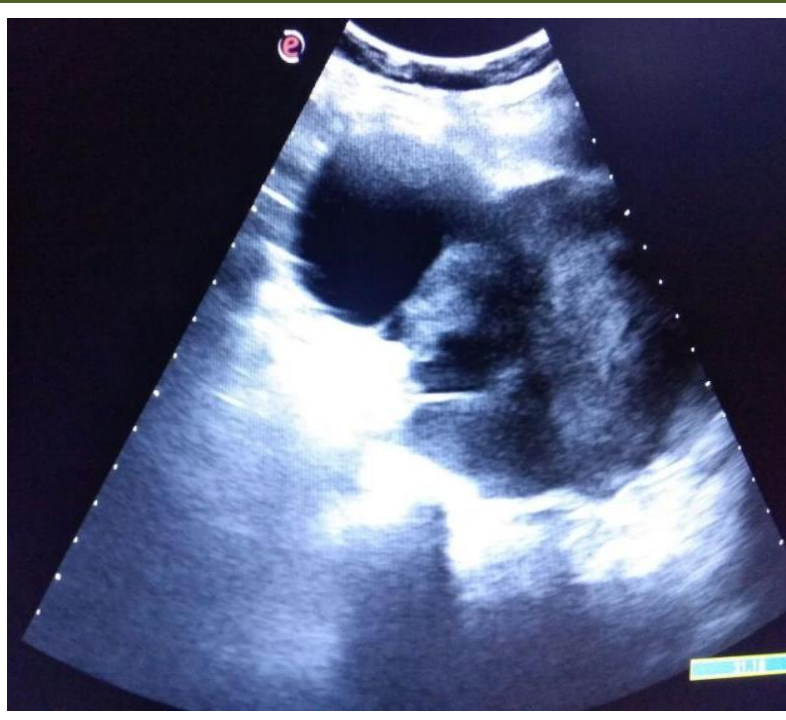

Case-5: 45 years female patient presented with abdominal pain.

T2 Heterointense lesion with cystic \& solid component in bilateral adnexa

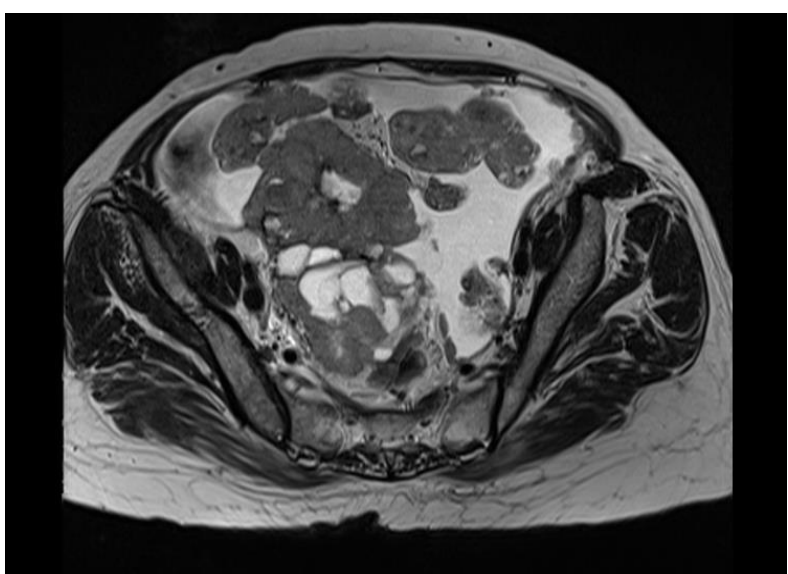

Cystic lesion with solid component noted in adnexa Malignant

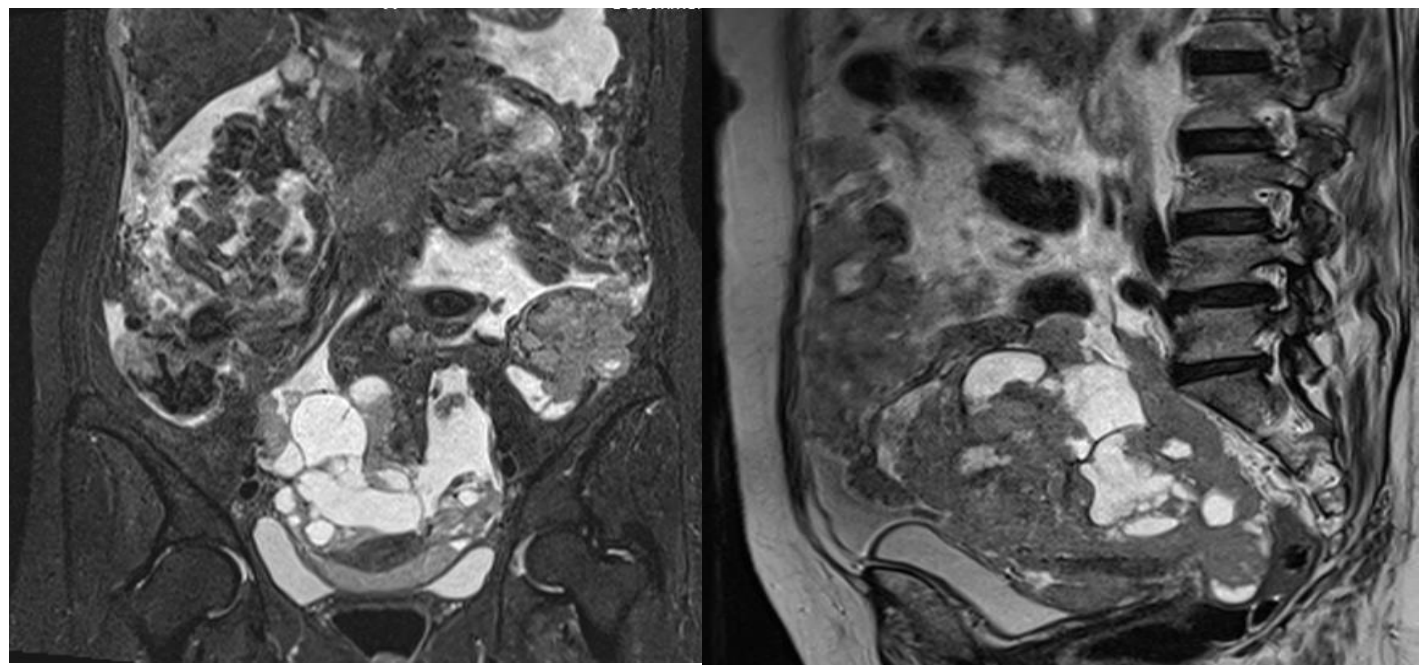

STIR Heterointense lesion with cystic \& solid component in bilateral adnexa with multiple omental deposits and ascites - Malignant 
RESULTS AND STATISTICAL ANALYSIS

The collected data were analyzed with IBM.SPSS statistics software 23.0 Version. To describe about the data descriptive statistics frequency analysis, percentage analysis were used for categorical variables and the mean \& S.D were used for continuous variables. analysis.

Bar chart and pie chart also used for statistical
The Receiver Operator Characteristic (ROC) curve analysis was used to find the Sensitivity, Specificity, PPV and NPV on comparison of USG with MRI.

In the above statistical tool the probability value .05 is considered as significant level.

\begin{tabular}{|l|l|l|}
\hline \multicolumn{3}{|c|}{ BILATERAL / UNILATERAL ADNEXAL MASS LESIONS } \\
\hline & Frequency & Percent \\
\hline Bilateral & 9 & 22.5 \\
\hline Unilateral & 31 & 77.5 \\
\hline Total & 40 & 100 \\
\hline
\end{tabular}

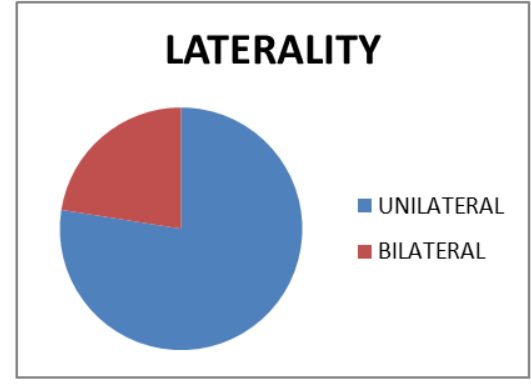

USG

\begin{tabular}{|l|l|l|}
\hline CONTENT - USG & \multicolumn{2}{|l|}{} \\
\hline Nature of lesion & Frequency & Percent \\
\hline Cystic & $\mathbf{3 0}$ & $\mathbf{7 5}$ \\
\hline Solid-cystic & 10 & $\mathbf{2 5}$ \\
\hline Total & $\mathbf{4 0}$ & $\mathbf{1 0 0}$ \\
\hline
\end{tabular}

\begin{tabular}{|l|l|l|}
\hline \multicolumn{2}{|l|}{ NODULE - USG } \\
\hline & Frequency & Percent \\
\hline Absent & $\mathbf{3 5}$ & $\mathbf{8 7 . 5}$ \\
\hline Present & $\mathbf{5}$ & $\mathbf{1 2 . 5}$ \\
\hline Total & $\mathbf{4 0}$ & $\mathbf{1 0 0}$ \\
\hline
\end{tabular}

\begin{tabular}{|l|l|l|}
\hline \multicolumn{2}{|l|}{ ASCITES - USG } \\
\hline & Frequency & Percent \\
\hline Absent & $\mathbf{3 5}$ & $\mathbf{8 7 . 5}$ \\
\hline Present & $\mathbf{5}$ & 12.5 \\
\hline Total & $\mathbf{4 0}$ & $\mathbf{1 0 0}$ \\
\hline
\end{tabular}

\begin{tabular}{|l|l|l|}
\hline VASCULARITY - USG \\
\hline & Frequency & Percent \\
\hline Absent & $\mathbf{3 4}$ & $\mathbf{8 2}$ \\
\hline Central vascularity & $\mathbf{3}$ & $\mathbf{1 0}$ \\
\hline Peripheral vascularity & $\mathbf{2}$ & $\mathbf{5}$ \\
\hline Septal vascularity & $\mathbf{1}$ & $\mathbf{2}$ \\
\hline Total & $\mathbf{4 0}$ & $\mathbf{1 0 0}$ \\
\hline
\end{tabular}

\begin{tabular}{|l|l|l|}
\hline \multicolumn{3}{|l|}{ SEPTUM CHARACTERISTICS - USG } \\
\hline & Frequency & Percent \\
\hline Absent & $\mathbf{2 6}$ & $\mathbf{6 5}$ \\
\hline Present & $\mathbf{1 4}$ & $\mathbf{3 5}$ \\
\hline Total & $\mathbf{4 0}$ & 100 \\
\hline
\end{tabular}

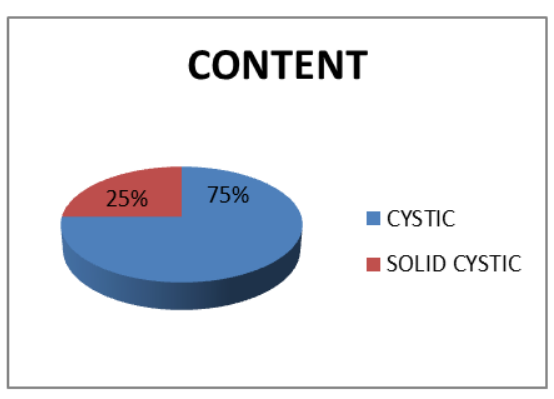

MRI

\begin{tabular}{|l|l|l|}
\hline CONTENT IN MRI \\
\hline Nature of lesion & Frequency & Percent \\
\hline Cystic & 30 & 75 \\
\hline Solid-cystic & 10 & 25 \\
\hline Total & 40 & 100 \\
\hline
\end{tabular}

\begin{tabular}{|l|l|l|}
\hline \multicolumn{2}{|l|}{ NODULE - MRI } \\
\hline & Frequency & Percent \\
\hline Absent & 34 & 85 \\
\hline Present & 6 & 15 \\
\hline Total & 40 & 100 \\
\hline
\end{tabular}

\begin{tabular}{|l|l|l|}
\hline \multicolumn{2}{|l|}{ ENHANCEMENT - MRI } \\
\hline & Frequency & Percent \\
\hline Enhancement & $\mathbf{1 2}$ & $\mathbf{3 0}$ \\
\hline No enhancement & $\mathbf{2 8}$ & $\mathbf{7 0}$ \\
\hline Total & $\mathbf{4 0}$ & $\mathbf{1 0 0}$ \\
\hline
\end{tabular}

\begin{tabular}{|l|l|l|}
\hline \multicolumn{3}{|c|}{ SEPTUM CHARACTERISTICS - MRI } \\
\hline & Frequency & Percent \\
\hline Absent & 26 & 65 \\
\hline Present & 14 & 35 \\
\hline Total & 40 & 100 \\
\hline
\end{tabular}

\begin{tabular}{|l|l|l|}
\hline ASCITES - MRI & \\
\hline & Frequency & Percent \\
\hline Absent & $\mathbf{3 5}$ & $\mathbf{8 7 . 5}$ \\
\hline Present & $\mathbf{5}$ & $\mathbf{1 3 . 5}$ \\
\hline Total & $\mathbf{4 0}$ & $\mathbf{1 0 0}$ \\
\hline
\end{tabular}


Atishi Gupta Aggarwal et al; Sch J App Med Sci, Jan, 2021; 9(1): 160-171

\begin{tabular}{|l|l|l|}
\hline \multicolumn{3}{|l|}{ OMENTAL DEPOSITS - MRI } \\
\hline & Frequency & Percent \\
\hline Absent & $\mathbf{3 8}$ & $\mathbf{9 5}$ \\
\hline Present & $\mathbf{2}$ & $\mathbf{5}$ \\
\hline Total & $\mathbf{4 0}$ & $\mathbf{1 0 0}$ \\
\hline
\end{tabular}

\begin{tabular}{|l|l|l|}
\hline MRI & Frequency & Percent \\
\hline + ve & $\mathbf{5}$ & 12.5 \\
\hline - ve & 35 & 87.5 \\
\hline Total & 40 & 100 \\
\hline
\end{tabular}

\begin{tabular}{|l|l|l|}
\hline \multicolumn{3}{|l|}{ LYMPHADENOPATHY - MRI } \\
\hline & Frequency & Percent \\
\hline Absent & $\mathbf{3 8}$ & $\mathbf{9 5}$ \\
\hline Present & $\mathbf{2}$ & $\mathbf{5}$ \\
\hline
\end{tabular}

\section{USG vs MRI}

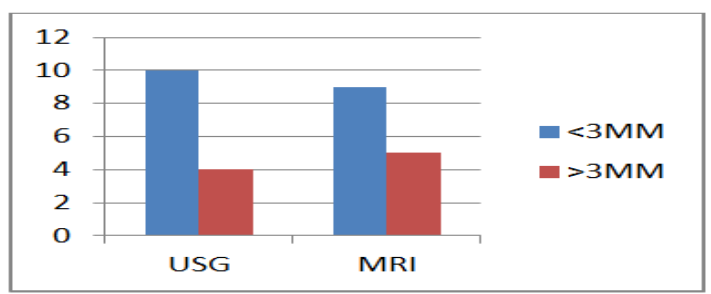

\begin{tabular}{|l|l|l|}
\hline HPE & Frequency & Percent \\
\hline + ve & 6 & 15 \\
\hline - ve & 34 & 85 \\
\hline Total & 40 & 100 \\
\hline
\end{tabular}

\begin{tabular}{|l|l|l|}
\hline USG & Frequency & Percent \\
\hline & 4 & 10 \\
\hline + ve & 4 & 90 \\
\hline - ve & 36 & 100 \\
\hline Total & 40 & \\
\hline
\end{tabular}

\begin{tabular}{|l|l|l|l|l|}
\hline \multicolumn{4}{|l|}{ USG * HPE Cross tabulation } \\
\hline \multicolumn{2}{|c|}{} & HPE & Total \\
\cline { 3 - 4 } \multicolumn{2}{|c|}{} & + ve & - ve & \\
\hline \multirow{3}{*}{ USG } & + ve & 4 & 0 & 4 \\
\cline { 2 - 4 } & - ve & 2 & 34 & 36 \\
\hline Total & 6 & 34 & 40 \\
\hline
\end{tabular}

\begin{tabular}{|l|l|}
\hline VARIABLES & PERCENTAGE \\
\hline Sensitivity & 66.6 \\
\hline Specificity & 100 \\
\hline PPV & 100 \\
\hline NPV & 94.4 \\
\hline
\end{tabular}

\begin{tabular}{|l|l|l|l|l|}
\hline \multicolumn{2}{|l|}{ MRI * HPE Crosstabulation } & Total \\
\cline { 3 - 5 } \multicolumn{2}{|l|}{} & HPE & - ve & \\
\cline { 2 - 5 } \multicolumn{2}{|l|}{ MRI } & + ve & 0 & 5 \\
\cline { 2 - 5 } & Te & 5 & 34 & 35 \\
\hline Total & 1 & 34 & 40 \\
\hline
\end{tabular}

\begin{tabular}{|l|l|}
\hline VARIABLES & PERCENTAGE \\
\hline Sensitivity & 83.3 \\
\hline Specificity & 100 \\
\hline PPV & 100 \\
\hline NPV & 97.1 \\
\hline
\end{tabular}

\begin{tabular}{|l|l|}
\hline \multicolumn{2}{|l|}{ ROC Curve } \\
\hline Case Processing Summary \\
\hline HPE & Valid N (list wise) \\
\hline Positive & 6 \\
\hline Negative & $\mathbf{3 4}$ \\
\hline
\end{tabular}

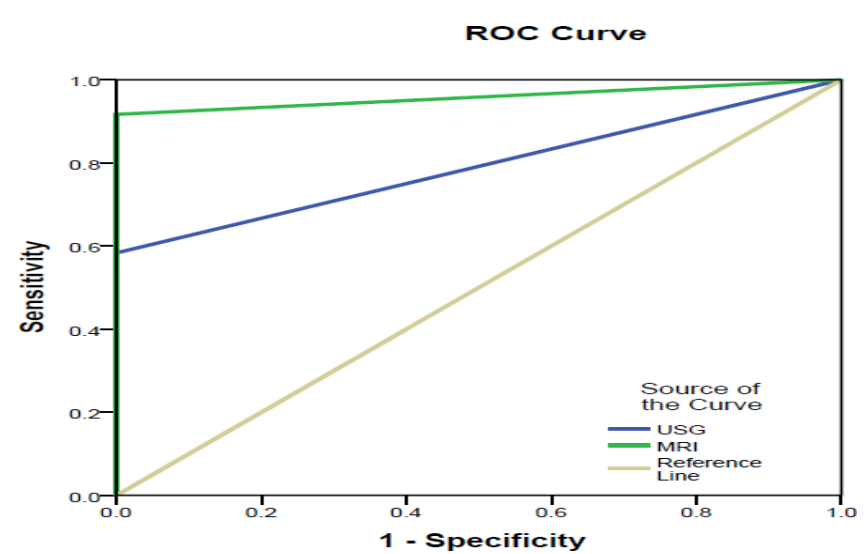

Graph-1: Septal thickness characteristics 
Smaller values of the test result variable(s) indicate stronger evidence for a positive actual state.

The test result variable(s): USG, MRI has at least one tie between the positive actual state group and the negative actual state group. Statistics may be biased.
1. Under the nonparametric assumption

2. Null hypothesis: true area $=0.5$

P- value is highly significant $<0.01$

\begin{tabular}{|l|l|l|l|l|l|}
\hline \multicolumn{2}{|l|}{ Age range } & Frequency & Percent & Valid Percent & Cumulative Percent \\
\hline \multicolumn{1}{|c|}{} & Upto 25 yrs & 15 & 37.5 & 37.5 & 37.5 \\
\hline & $26-35$ yrs & 6 & 15 & 15 & 52.5 \\
\cline { 2 - 6 } & $36-45$ yrs & 11 & 27.5 & 27.5 & 80.0 \\
\cline { 2 - 6 } & $46-55$ yrs & 4 & 10 & 10 & 90.0 \\
\cline { 2 - 6 } & Above 55 years & 4 & 10 & 10 & 100.0 \\
\cline { 2 - 6 } & Total & 45 & 100.0 & 100.0 & \\
\hline
\end{tabular}

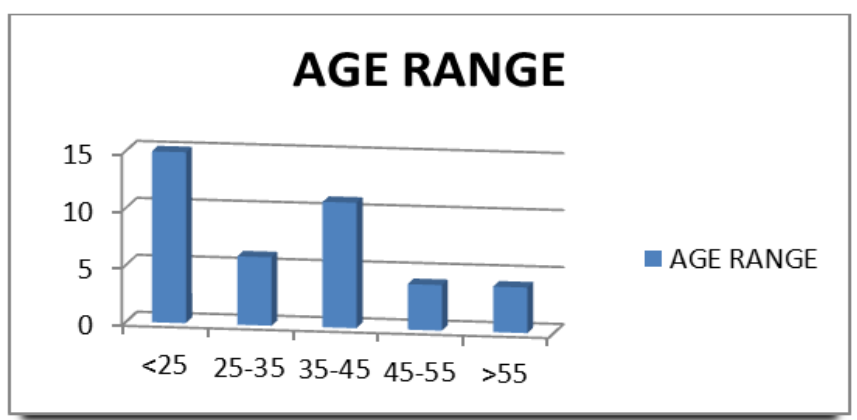

\section{RESULTS}

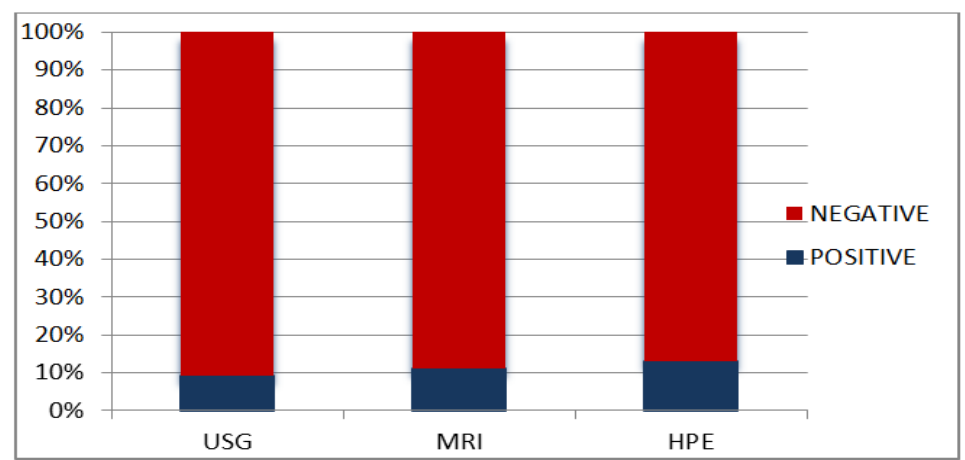

\begin{tabular}{|l|l|l|}
\hline Ovarian Tumors & Frequency & Percentage \\
\hline Benign serous cystadenoma & 6 & 15.0 \\
\hline Benign mucinous cystadenoma & 5 & 12.5 \\
\hline Teratoma/dermoid & 6 & 15.0 \\
\hline Malignant mucinous cystadenocarcinoma & 2 & 5.0 \\
\hline Serous papillary cystadenocarcinoma & 4 & 10.0 \\
\hline Polycystic ovarian disease & 3 & 7.5 \\
\hline Hydrosalpinx/pyosalpinx & 3 & 7.5 \\
\hline Ovarian hyperstimulation syndrome & 1 & 2.5 \\
\hline Corpus luteal cyst & 1 & 2.5 \\
\hline Haemorrhagic/endometriotic cyst & 9 & 22.5 \\
\hline
\end{tabular}




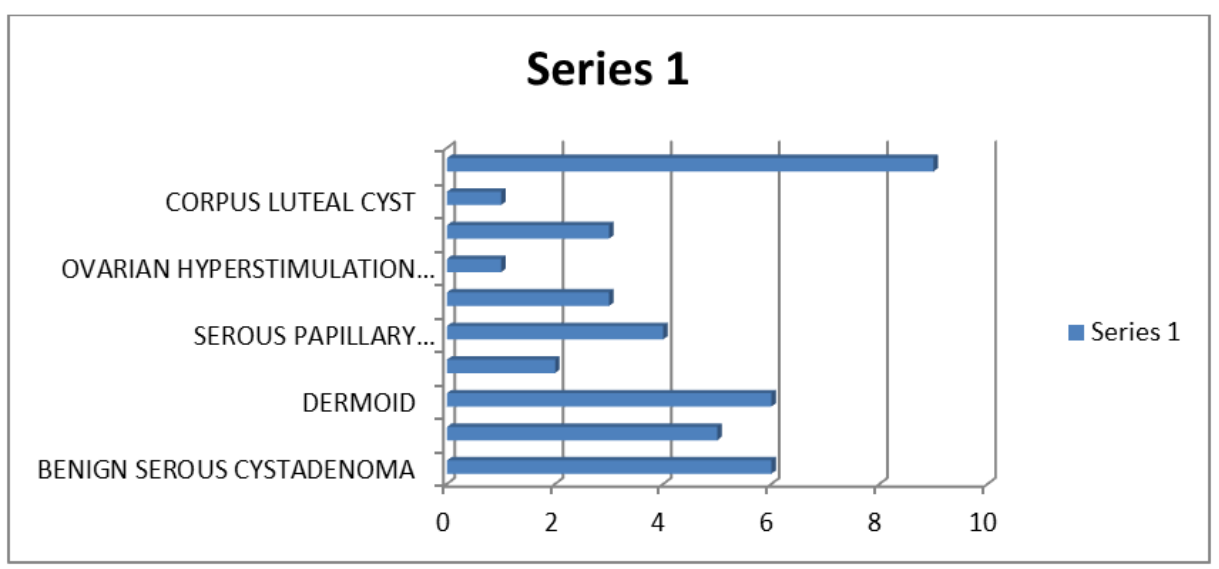

\section{DisCUSSION}

The age group examined in our study was from 16 -76 years. Among these the incidence of adnexal lesions were found to be more in the age group of $<25$ years and followed by 35-45 years.

Among these 40 patients, 9 had bilateral lesions and 31 had unilateral lesions.

In Ultrasonogram adnexal lesions were evaluated for several features including content, nodularity, wall thickness, septal thickness, ascites and vascularity of the lesion.

In our study group solid cystic nature of the lesion was seen in 25\% (10 cases), Septal thickness > $3 \mathrm{~mm}$ in 4 cases, nodularity was seen in $12.5 \%$ ( 5 cases) and central / septal vascularity was seen in $10.0 \%$ (4 cases).

Among these, all the cases having central and septal vascularity were found to be malignant.

The Dynamic MR imaging features documented for evaluation include the lesion size, content of lesion (solid only, mainly solid, solid-cystic, mainly cystic, and cystic only), wall thickness, nodularity, septal thickness, early arterial phase enhancement, ascites, omental deposits and lymphadenopathy.

Solid - cystic nature of the lesion was seen in $25 \%$ (10 cases), septal thickness $>3 \mathrm{~mm}$ was seen in 5 cases, nodularity was seen in $15.0 \%$ and early arterial phase enhancement was seen in $12.5 \%$ (5 case) are highly indicative of malignant ovarian tumors.

The study included 40 patients with adnexal mass lesions. On Ultrasonogram there were 36 cases of benign ovarian lesions and 4 cases of malignant ovarian tumors. MR imaging studies of 40 patients showed 35 cases to be of benign nature and 5 cases to be of malignant nature. Histopathological studies of postoperative specimens reveled 34 cases to have benign tumor and 6 cases to have malignant features.
Sohaib et al., [16] showed that from the analysis of the MR imaging features, "the most predictive characteristics of malignancy are vegetations/nodule in a cystic lesion, presence of ascites, a maximal diameter greater than $6 \mathrm{~cm}$, and necrosis in a solid lesion" in the same way our study also shows the presence of nodules in a cystic lesion, presence of ascites and lesion size more than $6 \mathrm{~cm}$ suggestive of malignancy.

Valentini et al., [10] suggested criteria for characterization of suspicious adnexal lesions. Features suggestive of malignancy as per the valentine et al study were "solid, solid/cystic enhancing masses (greater than $4 \mathrm{~cm}$ in maximum diameter) with papillary projections and irregular thick wall and septa greater than $3 \mathrm{~mm}$ ) into a cystic lesion" as well as a "heterogeneous and early enhancement pattern". Similar to this study, the above features in our study population also had positivity for malignancy.

Adumusili et al., [11] study have high specificity (94\%) for establishing a benign diagnosis. The specificity in our study is $100 \%$.

Guerra et al., study [9] on MRI had a higher accuracy of $95 \%$ in differentiating between malignant and non-malignant adnexal lesions. The diagnostic accuracy of our study is $95 \%$ similar to Guerra et al., [9].

Adumusili et al., study [11] showed Sonographically indeterminate ovarian mass lesions evaluated with MRI had a sensitivity and specificity of $100 \%$ and $94 \%$, respectively. Result of our study MRI had a sensitivity of $91.7 \%$ and specificity of $100 \%$.

Sohaib et al., study [16] showed overall diagnostic accuracy of $91 \%$ for distinguishing MR imaging features of benign from malignant adnexal lesions. The results of our study show that the overall diagnostic accuracy of $95 \%$ for distinguishing benign from malignant adnexal lesions. 
Features that were shown not to be significantly different between benign and malignant masses in our study were wall thickness and size of the lesion.

In MRI characterization of adnexal mass lesions, enhancement of lesion, septal thickness $>3 \mathrm{~mm}$, nodularity of the lesion and ascites are highly suggestive of malignant nature of the lesion.

In Ultrasonographic characterization of adnexal mass lesions, septal thickness, nodularity, central and peripheral vascularity of the lesion are highly suggestive of malignancy.

The sensitivity, specificity, positive predictive value and negative predictive value of Ultrasonogram in comparison with HPE were $66.6 \%, 100 \%, 100 \%$, $93.3 \%$ respectively.

In comparison with HPE, characterization of the detected lesions as malignant, MR imaging had a sensitivity of $83.3 \%$, specificity of $100 \%$, positive predictive value of $100 \%$, and negative predictive value of $97.1 \%$.

\section{CONCLUSION}

Inspite of development in advanced chemotherapy regimens and improved surgical approaches, ovarian carcinoma continues to be one of the leading cause of death from gynaecological malignancy.

Treatment of adnexal mass lesion mandates stratification of risk based on imaging appearance of the mass.

MRI, because of its accuracy in identifying the origin of adnexal mass and characterizing the solid, hemorrhagic, fatty and fibrous content, may obviate surgery or significantly contribute to preoperative planning for a sonographically indeterminate mass.

MRI is the state-of-the-art imaging modality for evaluation of adnexal masses with an overall high sensitivity and high diagnostic accuracy. Although ultrasonography is the initial imaging modality of choice for evaluation of adnexal mass lesions.

Transvaginal approach is a useful adjunct to transabdominal because it adds specificity in determining extraovarian masses and endometrial and myometrial disorders. Transvaginal sonography affords an accurate means for evaluation of the ovaries and is particularly useful in obese, postmenopausal women in whom the incidence of ovarian carcinoma is especially high.
Color Doppler sonography seems to be helpful in distinguishing benign from malignant ovarian masses and in the evaluation of adnexal torsion. It is particularly useful as an adjunct to morphologic assessment of ovarian lesions.

\section{REFERENCES}

1. BD Chaurasia human anatomy, regional and applied, dissection and clinical, volume 2- lower limb and abdomen \& pelvis 4 th edition.

2. Grays henry anatomy 41 st edition.

3. Cunningham DJ. Cunninghams text book of anatomy.

4. Togashi K. Ovarian cancer: the clinical role of US, CT, and MRI. EurRadiol. 2003; 13 Suppl 4:L87104.

5. Veena R. Iyer1 and Susanna I. Lee. MRI, CT, and PET/CT for Ovarian Cancer Detection and Adnexal Lesion Characterization. American Journal of Roentgenology. 2010; 194:311-321. 10.2214/AJR.09.3522.

6. Kinkel K, Lu Y, Mehdizade A, Pelte MF, Hricak $\mathrm{H}$. Indeterminate ovarian mass at US: incremental value of second imaging test for characterization-meta-analysis and Bayesian analysis. Radiology. 2005; 236:85-94.

7. Reles A, Wein U, Lichtenegger W. Transvaginal color Doppler sonography and conventional sonography in the preoperative assessment of adnexal masses. J Clin Ultrasound. 1997; 25:217225.

8. Kurtz AB, Tsimikas JV, Tempany CM, Hamper UM, Arger PH, Bree RL, Wechsler RJ, Francis IR, Kuhlman JE, Siegelman ES, Mitchell DG. Diagnosis and staging of ovarian cancer: comparative values of Doppler and conventional US, CT, and MR imaging correlated with surgery and histopathologic analysis - report of the Radiology Diagnostic Oncology Group. Radiology. 1999 Jul;212(1):19-27.

9. Hricak H, Chen M, Coakley FV, Kinkel K, Yu KK, Sica G, Bacchetti P, Powell CB. Complex adnexal masses: detection and characterization with MR imaging-multivariate analysis. Radiology. 2000 Jan;214(1):39-46.

10. Valentini AL, Gui B, Miccò M, Mingote MC, De Gaetano AM, Ninivaggi V, Bonomo L. Benign and suspicious ovarian masses-MR imaging criteria for characterization: pictorial review. Journal of oncology. 2012 Jan 1;2012.

11. Adusumilli S, Hussain HK, Caoili EM, Weadock WJ, Murray JP, Johnson TD, Chen Q, Desjardins B. MRI of sonographically indeterminate adnexal masses. AJR Am J Roentgenol. 2006; 187:732740 .

12. Van Vierzen PB, Massuger LF, Ruys SH, Barentsz JO. Borderline ovarian malignancy: ultrasound and fast dynamic MR findings. Eur $\mathrm{J}$ Radiol. 1998; 28:136-142. 
13. Saini A, Dina R, McIndoe GA, Soutter WP, Gishen P, deSouza NM. Characterization of adnexal masses with MRI. Am J Roentgenol. 2005; 184:1004-9.

14. Kawamoto S, Urban BA, Fishman EK. CT of epithelial ovarian tumors. Radiographics. 1999;19.

15. Jeong YY, Outwater EK, Kang HK. Imaging evaluation of ovarian masses. Radio Graphics. 2000; 20:1445-1470.

16. Sohaib SA, Sahdev A, Van Trappen P, Jacobs IJ, Reznek RH. Characterization of adnexal mass lesions on MR imaging. Am J Roentgenol. 2003; 180:1297-304.

17. www.pathologyoutlines.com/topic/ovarytumourw hoclassif.html

18. Javadi S, Ganeshan DM, Qayyum A, Iyer RB, Bhosale P. Ovarian cancer, the revised FIGO staging system, and the role of imaging. American Journal of Roentgenology. 2016 Jun;206(6):135160 . 